Article

\title{
Evaluating the Pricing Strategy for Change Orders between General Contractors and Subcontractors Using ET-SD Model
}

\author{
Chien-Liang Lin, Ph.D ${ }^{1}$, Yu-Che Lai, Ph.D ${ }^{2 *}$ \\ 1 Professor, Dept. of Construction Engineering, National Kaohsiung Univ. of Science and Technology; \\ ken@nkust.edu.tw \\ 2 Ph.D Program in Engineering Science and Technology, National Kaohsiung Univ. of Science and Technology; \\ larich88@gmail.com \\ * Correspondence: larich88@gmail.com;
}

\begin{abstract}
Change orders have received considerable attention from researchers thus far, but none have considered pricing strategies of change orders through the interaction between general contractors and subcontractors. Previous studies found that contractors' opportunistic bidding considering beyond-contractual reward (BCR) in the execution stage can be reduced by improving the construction management system and strengthening the supervision of contractors' performance. However, the BCR remains in ecology of construction engineering. This study proposes an integrated evolutionary game theory-system dynamics model (ET-SD model) and simulates the pricing strategy of change orders between general contractors and subcontractors to explore the root cause of BCR phenomenon. Sensitivity analysis on the evolutionary dynamics of payoff is explored. Results reveal that change orders with BCR maintain Nash equilibrium and evolutionary stable strategy (ESS) unless changing the payoff structure between general and subcontractors' pricing strategies. This study presents important managerial insights from the evolutionary game perspectives, nature of change orders, and payoff of the alternative.
\end{abstract}

Keywords: Change order, Pricing, Game Theory, Evolutionary stable strategy (ESS), System Dynamics

\section{Introduction}

In a large EPC project, time pressures frequently brought about by overlapping design, procurement, and construction increase uncertainty and complexity in managing multiple interfaces among different interacting stakeholders [1]. Change orders are inevitable due to the intense variable construction environment [2,3]. Although change orders might improve the original deliverables of project execution, they cause impact on original project time, cost, quality and resource allocation which reflect the price of change order. They might also obstruct the success of project and erode the profit earned if the final price cannot be settled by the owner and the contractor. However, in previous studies of change order, few have considered their pricing strategies.

In the execution stage, change orders often involve time pressure, work complexity, and interface with existing works, pricing in the traditional bidding system may not be applicable to change orders. Furthermore, when a contractor wins the bid by the lowest price but gains extortionate profit beyond the contract by change orders, it is always a big concern for owners. Having said that, pricing of change orders has been focused on illustrating a general rule from either the owner's or contractor's perspective, no research has considered a dynamic evaluation between them. Therefore, reducing the pricing controversy incurred by change orders remains difficult. 
To fill this gap, this study applies evolutionary game theory (ET) and creates a pricing model of change orders using system dynamics (SD). The theory breaks through the rationality assumption in the traditional game theory using the mechanism of biological evolution and discussing the Nash equilibrium (NE) with evolutionary stable strategies (ESSs). SD can visualize the evolutionary process of change order pricing and reveal important managerial insights by changing critical variables.

In consideration of sustainable relationship between general contractors and subcontractors, this study aims to explore the evolutionary dynamics of different pricing strategies of change orders, providing industry practitioners with a reference of pricing on change orders.

The remainder of this paper is organized as follows. Section 2 presents a critical review on change orders, the relationship between general contractor and subcontractors, and a brief explanation of ET and SD. Section 3 describes model formulation, and Section 4 presents a simulation. Section 5 provides the discussion and sensitivity analysis. Section 6 presents conclusions and recommendations for future research.

\section{Literature Review}

\subsection{Change order between general contractors and subcontractors}

Change, defined as any event resulting in a modification of the original scope, execution time, or cost of work, is inevitable on most construction projects [4]. Various studies have examined different aspects of change orders, including risk assumption of change orders[5], change orders' impact on labor productivity [6-8], property and causes of change orders [9], timing of change [8,10], change process management [11-13], and cooperation between owners and contractors [14]. However, few have discussed the pricing of change orders.

Change orders involved abovementioned factors are complicate to evaluate the reasonable pricing. Therefore, a bidder in the bidding market might submit an abnormal low price to win the bid and recover the profit from a future claim [15], recapture money [16], or obtain a beyond-contractual reward (BCR) in the project execution stage [17].

Lo et al. found that improvements in the construction management system of projects are crucial to lower the possibility that contractors gain BCR and engage in opportunistic bidding and further enhance project quality [17]. Lo and Yan further indicated that contractors' opportunistic bidding behavior can be reduced only when general contractors' past performance is carefully and constantly examined and closely reflected in the bid evaluation [18]. Although they facilitate the reduction of BCR through management, change orders with BCR remain in the construction ecology.

Besides, subcontractors play a vital role by performing $80 \%-90 \%$ of the construction work in the construction industry [5]. Competitive relationships and payoffs between general contractors and original subcontractors may influence the pricing strategy of change orders.

Lee et al. revealed that in a competitive relationship, general contractors generally assume that subcontractors will deliver the utmost performance and abstain from opportunistic behavior [14]. However, in strategic partnerships, although this relationship type has various advantages, general contractors cannot easily forestall subcontractors' opportunistic behavior, particularly when transaction-specific investment is involved. Furthermore, subcontractors may become more ambitious in earning more after maintaining long-term relationships with main contractors [19,20]. Thus, general contractors become more difficult to negotiate with than original subcontractors for change orders correlating with the original scope of work before the latter implements the changes.

Ren and Anumba indicated that a party may adopt a time-consuming strategy to benefit from an opponent's time pressure or emotional exhaustion during the negotiation process [21]. Therefore, owing to time limits and the long-term relationships with subcontractors, general contractors may compromise the quotation with BCR.

Paul indicated that the pricing elements of change orders or claims include the direct cost of performing the changed work, impact and/or delayed performance costs, and markups [22]. Duah and Syal developed a standard process using a weighted system to estimate the direct and indirect costs of 
change orders [23]. The argument may be decreased among stakeholders through a standard pricing of change orders regulated in the contract specification. However, it might not illustrate a complete figure of pricing dynamic between general contractors and subcontractors.

In sum, the impact of change orders on construction projects is intricate; thus, the pricing of change orders may not have a one-size-fits-all solution. Previous studies indicated that strict construction management and supervision are beneficial for reducing subcontractors' optimistic bidding and BCR. However, change orders with BCR remains in the construction ecology and have been worried by owners. In light of the importance of subcontractors to construction projects, pricing strategy may take into account the relationship between general contractors and subcontractors. Preventing the pricing of change orders from becoming a dispute necessitates realizing the strategic dynamics of pricing between both parties. ET and SD are reviewed in the next section for model formulation.

\subsection{Evolutionary game theory}

Game theory is defined as the study of strategic choices interacted among rational players adopting the best strategy by considering other players' strategies. Decision-makers in the game clearly know that their behavior will influence others' behaviors [24]. However, the hypothesis on intelligent rational players is inconsistent in the real world. Traditional game theory neglects the dynamics process of game playing. Compared with the traditional game theory, ET combines concepts from biology, evolution, nonlinear dynamics, and game theory with dynamic evolutionary process analysis. It was developed to overcome the disadvantages of the traditional game theory when analyzing the bounded rationality of players and dynamic process of game playing [25]. Each player chooses among alternative actions or behaviors whose payoff or fitness depends on the choices of others [26]. The distribution of observed behavior in a population evolves over time as fitter strategies thrive and less fit strategies are displaced and eventually die out. ET determines the relationship between NE and ESSs, as originated by Maynard Smith [27]. NE is explained as the long run outcome of an adaptive process [28]. The replicator dynamics is a mechanism to quantify dynamic behavior and prestige-biased learning in evolutionary games and indicates that the proportion of population to adopt a strategy will increase if the difference of the strategy payoff and the average payoff of all strategies increases [29].

Construction projects are not too dissimilar from serious "games" that make insights from game theory useful to understanding partnering relationship [30]. In construction projects, general contractors and subcontractors usually change and dynamically adjust their pricing strategies by observing and comparing payoffs with others via each change orders. Therefore, ET is more applicable to exploring the long-term (but finite) dynamics equilibrium of change order pricing between contractors and subcontractors.

\subsection{ET-SD model}

Although game theory is powerful in exploring the long-term behavior of systems, it reveals little about the transient time of the games. Numerous studies in different fields integrate it with SD for a better understanding of the dynamic behavior in a system. The SD model helps simulate and visualize the feedback process of replicator dynamics.

SD is an approach developed by Forrester in 1961 for studying the behavior of systems exhibiting high dynamic complexity. It can simulate the behavior of feedback loops and visualize interactions among elements through the stock flow diagram.

Kim and Kim integrated a mixed-strategy game into a SD model to investigate the interaction between police and drivers [31]. Tian et al. developed a SD model based on ET to guide subsidy policies to promote the diffusion of green supply chain management in China [32]. Liu et al. created a SD model using ET to describe the interaction among the stakeholders in China's coal mining safety inspection system [33]. Mohammadi et al. evaluated the competitive behavior of firms in an oligopolistic market based on a hybrid of SD and game theory. Guo et al. used an SD model based on ET for quality supervision among construction stakeholders [34]. 
In sum, general contractors and subcontractors are two major roles in construction project. Pricing of change order between general contractors and subcontractors take a critical and dynamic process under project execution. Therefore, ET-SD model is utilized to explore the process.

\section{Model formulation}

This section may be divided by subheadings. It should provide a concise and precise description of the experimental results, their interpretation as well as the experimental conclusions that can be drawn.

In ET, a population game played by a society comprises one or more populations $\mathrm{p} \in \mathrm{P}=$ $\{1, \ldots, p\}$. Each population $p$ contains agents who choose pure strategies from the set $S^{p}=\left\{1, \ldots, n^{p}\right\}$. The proportion of population $p$ employing the pure strategy $s$ is denoted by $x_{s}^{p} \in[0,1]$. Accordingly, a population state $\mathrm{x}^{\mathrm{p}}=\left(\mathrm{x}_{1}^{\mathrm{p}}, \ldots, \mathrm{x}_{\mathrm{n}}^{\mathrm{p}}\right)$ indicates the proportion of population $\mathrm{p}$ employing each pure strategy $s \in S^{p}$. Let $m=\sum_{s=1}^{p} n_{p}$, so a social state $x=\left(x^{1}, \ldots, x^{p}\right) \in R^{m}$ describes the state of all population $\mathrm{p} \in \mathrm{P}$. The payoff to an agent $\mathrm{i}$ in population $\mathrm{p}$ who employs pure strategy $\mathrm{s}$ is given by the payoff function $\pi^{\mathrm{p}}\left(\mathrm{s}_{\mathrm{i}}, \mathrm{s}_{-\mathrm{i}}\right)$ when opponents of an agent $\mathrm{i}$ play strategy $\mathrm{s}_{-\mathrm{i}}$. An agent $\mathrm{i}$ adopting strategy $s^{*}$ in a social state $x$ is said to have an ESS when

$$
\pi^{\mathrm{p}}\left(\mathrm{s}^{*}, \mathrm{~s}^{*}\right)>\pi^{\mathrm{p}}\left(\mathrm{s}^{\prime}, \mathrm{s}^{*}\right)
$$

or

(a) $\pi^{\mathrm{p}}\left(\mathrm{s}^{*}, \mathrm{~s}^{*}\right)=\pi^{\mathrm{p}}\left(\mathrm{s}^{\prime}, \mathrm{s}^{*}\right)$ and $(\mathrm{b}) \pi^{\mathrm{p}}\left(\mathrm{s}^{*}, \mathrm{~s}^{\prime}\right)>\pi^{\mathrm{p}}\left(\mathrm{s}^{\prime}, \mathrm{s}^{\prime}\right)$

Strategy $s^{*}$ will not be invaded by strategy $s^{\prime}$ if Eq. (1) holds. Moreover, strategy $s^{\prime}$ will motivate $s^{*}$ but harm itself if Eq. (2) holds. Equations (1) and (2) identify strong NE and weak NE, respectively.

According to the concept of replicator dynamics, the changing rate of $\mathrm{x}_{\mathrm{s}}^{\mathrm{p}}$ is as follows:

$$
\dot{\mathrm{x}}_{\mathrm{s}}^{\mathrm{p}}=\sum_{\mathrm{t}=1} \mathrm{x}_{\mathrm{s}}^{\mathrm{p}} \pi_{\mathrm{s}}^{\mathrm{p}} \mathrm{q}_{\mathrm{ts}}^{\mathrm{p}}-\varphi(\mathrm{x}, \pi) \mathrm{x}_{\mathrm{s}}^{\mathrm{p}}
$$

Where $x_{s}^{p}$ means the proportion of population $p$ to employ pure strategy $s, \sum_{t=1} x_{s}^{p}=1, \pi_{s}^{p}$ means payoff (fitness), $\mathrm{q}_{\mathrm{ts}}^{\mathrm{p}}$ means behavior change (mutation), and $\varphi(\mathrm{x}, \pi) \mathrm{x}_{\mathrm{s}}^{\mathrm{p}}$ means average payoff.

This study considers general contractor-subcontractor pricing games played by two large populations of general contractors $(C)$ and original subcontractors $(S)$, denoted as $p=\{C, S\}$. Each general contractor's change order chooses one of two symmetrical strategies $s^{C}=\{C O B, C P B\}$ to prepare the budget. Each original subcontractor's response chooses one of two symmetrical strategies $\mathrm{S}^{\mathrm{S}}=\{\mathrm{SHQ}, \mathrm{SNQ}\}$ to submit the quotation.

$\mathrm{COB}$ refers to the budget strategy prepared by general contractor for inquiring the original subcontractor. CPB refers to the budget prepared by the general contractor for further inquiries with another potential subcontractor. SHQ is the strategy of high quotation, which the original subcontractor submits to the general contractor (i.e., quotation with BCR considering cooperation with the owner (Lee et al. 2009), time pressure (Ibbs 2005) or risk assumption (Hinze and Tracey 1994)). SNQ is the normal quotation strategy submitted by the original subcontractor to the general contractor. Compared with a normal quotation, the higher quotation usually leads to a higher payoff. However, the differentiation between SHQ and SNQ has no clear criteria. In principle, they can be useful for the general contractor's judgment if the final amount of change orders is over the budget or the discounting ratio for change orders is much less than the original contract.

Accordingly, the payoff matrix between the general contractors and original subcontractors is shown in Figure 1. 


\begin{tabular}{|c|c|c|c|c|}
\cline { 3 - 5 } \multicolumn{2}{c|}{} & \multicolumn{2}{c|}{ Subcontractor (S) } & \multicolumn{1}{c|}{ proportion } \\
\cline { 3 - 5 } \multicolumn{2}{c|}{} & SHQ & SNQ & $x_{s}^{C}$ \\
\hline \multirow{3}{*}{ Contractor (C) } & $\mathrm{COB}$ & $(\mathrm{OB} 1, \mathrm{HQ} 1)$ & $(\mathrm{OB} 2, \mathrm{NQ} 1)$ & $1-x_{s}^{C}$ \\
\cline { 2 - 5 } & $\mathrm{CPB}$ & $(\mathrm{PB} 1, \mathrm{HQ} 2)$ & $(\mathrm{PB} 2, \mathrm{NQ} 2)$ & \\
\hline & proportion & $x_{s}^{S}$ & $1-x_{s}^{S}$ & \\
\cline { 3 - 5 } & & &
\end{tabular}

Figure 1. The payoff matrix between general contractors and original subcontractors

The payoffs or fitness of $s^{C}$ is

$$
\begin{aligned}
& \pi_{\mathrm{COB}}=\mathrm{x}_{\mathrm{s}}^{\mathrm{S}} \mathrm{OB} 1+\left(1-\mathrm{x}_{\mathrm{s}}^{\mathrm{S}}\right) \mathrm{OB} 2 \\
& \pi_{\mathrm{CPB}}=\mathrm{x}_{\mathrm{S}}^{\mathrm{S}} \mathrm{PB} 1+\left(1-\mathrm{x}_{\mathrm{S}}^{\mathrm{S}}\right) \mathrm{PB} 2
\end{aligned}
$$

The replicator dynamics of population $\mathrm{C}$ is calculated by the quotient rule:

$$
\begin{gathered}
\dot{x}_{\mathrm{s}}^{\mathrm{C}}=\mathrm{x}_{\mathrm{s}}^{\mathrm{C}}\left(\pi_{\mathrm{COB}}-\left(\mathrm{x}_{\mathrm{s}}^{\mathrm{C}} \pi_{\mathrm{COB}}+\left(1-\mathrm{x}_{\mathrm{s}}^{\mathrm{C}}\right) \pi_{\mathrm{CPB}}\right)\right) \\
\dot{\mathrm{x}}_{\mathrm{s}}^{\mathrm{C}}=\mathrm{x}_{\mathrm{s}}^{\mathrm{C}}\left(1-\mathrm{x}_{\mathrm{s}}^{\mathrm{C}}\right)\left(\pi_{\mathrm{COB}}-\pi_{\mathrm{CPB}}\right)
\end{gathered}
$$

Similarly, the payoffs or fitness of $s^{S}$ is

$$
\begin{aligned}
& \pi_{\mathrm{SHQ}}=\mathrm{x}_{\mathrm{S}}^{\mathrm{C}} \mathrm{HQ} 1+\left(1-\mathrm{x}_{\mathrm{s}}^{\mathrm{C}}\right) \mathrm{SQ} 2 \\
& \pi_{\mathrm{SNQ}}=\mathrm{x}_{\mathrm{S}}^{\mathrm{C}} \mathrm{NQ} 1+\left(1-\mathrm{x}_{\mathrm{S}}^{\mathrm{C}}\right) \mathrm{NQ} 2
\end{aligned}
$$

The replicator dynamics of population $S$ is

$$
\dot{\mathrm{x}}_{\mathrm{S}}^{\mathrm{S}}=\mathrm{x}_{\mathrm{S}}^{\mathrm{S}}\left(1-\mathrm{x}_{\mathrm{S}}^{\mathrm{S}}\right)\left(\pi_{\mathrm{SHQ}}-\pi_{\mathrm{SNQ}}\right)
$$

The ET-SD model is established by Vensim PLE x32 in this study in accordance with the above assumption (Figure 2).

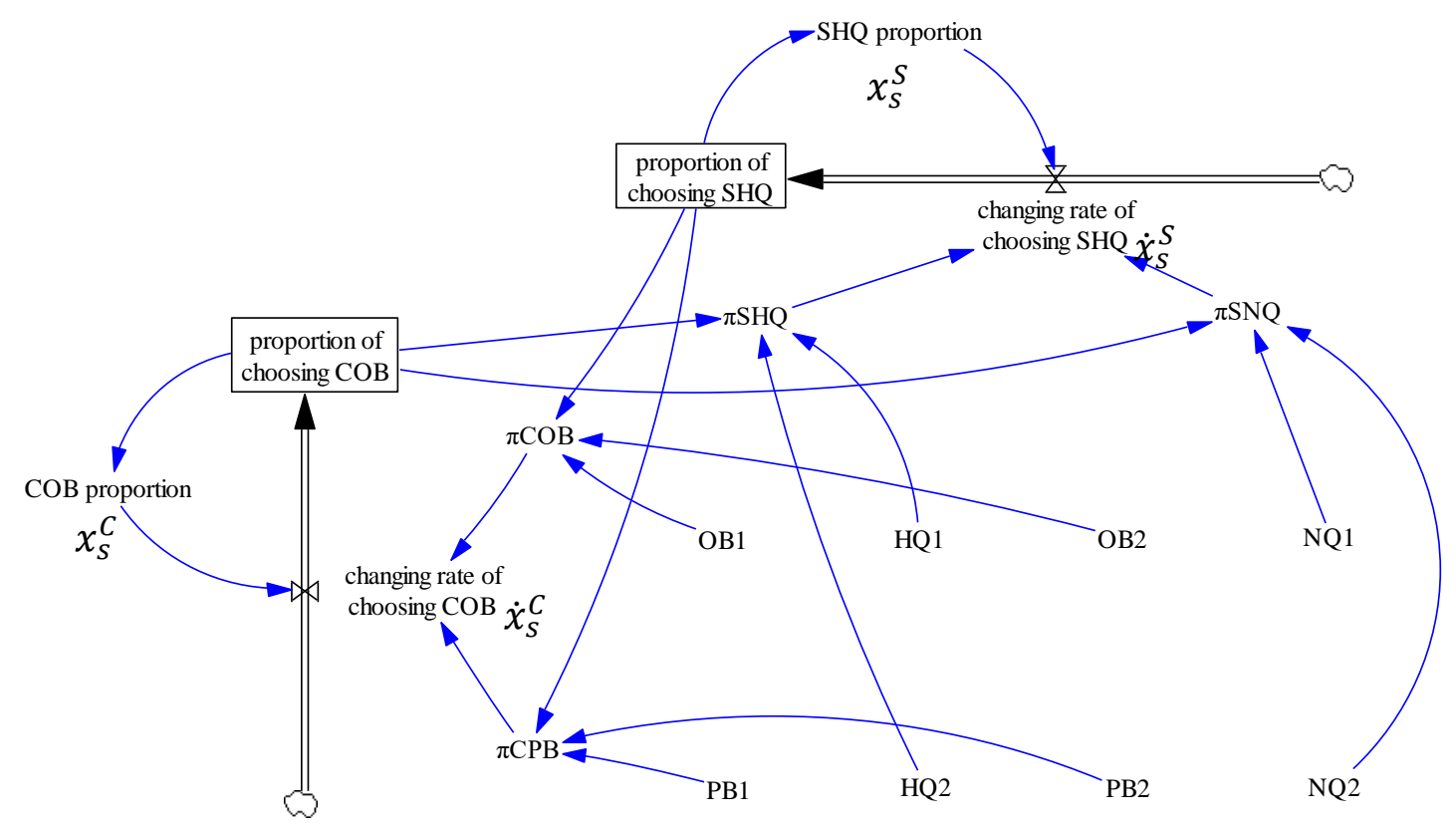

Figure 2. Pricing dynamics between general contractors and subcontractors

The ET-SD model includes two stock variables, two flow variables, four auxiliary variables, and eight external variables. Stock variables involve the proportion of the general contractors choosing COB and the proportion of the subcontractors choosing SHQ. Flow variables represent the 
decision-making process of replicator dynamics adopted by the general contractors and subcontractors. Auxiliary variables denote the payoff of each strategy taken by the general contractors and subcontractors considering the proportion of each strategy taken by opponents (Eqs. (4), (5), (8) and (9)). External variables identify the payoff of each pure strategy adopted by the general contractors and subcontractors considering the circumstance of the change orders.

\section{Model simulation}

The system dynamic model based on replicator dynamics can simulate the dynamic outcome of evolutionary game theory. It can be applied to evolutionary game theory of two populations. Therefore, a typical example Hawk-Dove game is adopted from Roger (2006) to validate the model.

Assume there are two populations of bird which characterize hawk (aggressive) and dove (peaceful). The proportion of hawkish bird in each population is identified as $\mathrm{z}$ and the proportion of dovish bird is 1-z. the symmetric bi-matrix game is shown as Figure 3.

\begin{tabular}{|c|c|c|c|c|}
\cline { 3 - 5 } \multicolumn{2}{c|}{} & \multicolumn{2}{c|}{ Population B } & \multicolumn{1}{c}{} \\
\cline { 3 - 5 } \multicolumn{2}{c|}{} & Hawk & Dove & proportion \\
\hline \multirow{3}{*}{ Population A } & Hawk & $(-25,-25)$ & $(14,-9)$ & $z$ \\
\cline { 2 - 5 } & Dove & $(-9,14)$ & $(5,5)$ & $1-z$ \\
\hline & proportion & $z$ & $1-z$ & \\
\cline { 2 - 5 } & & &
\end{tabular}

Figure 3. Hawk-Dove payoff matrix

The expected payoff of adopting hawkish act is as follows:

$$
\mathrm{EV}(\mathrm{H})=(-25 \mathrm{z})+14(1-\mathrm{z})=14-39 \mathrm{z}
$$

The expected payoff of adopting dovish act is as follows:

$$
\mathrm{EV}(\mathrm{D})=(-9 \mathrm{z})+5(1-\mathrm{z})=5-14 \mathrm{z}
$$

Two populations will achieve the NE and become ESS when EV (H) is equal to EV (D). $z=9 / 25$. Any mutant occurred cannot survive in each population.

On the other hand, the ET-SD model is utilized to simulate the example and NE can be acquired at the same value, as shown in Figure 4.

\section{Game results exist mutation (Hwak)}

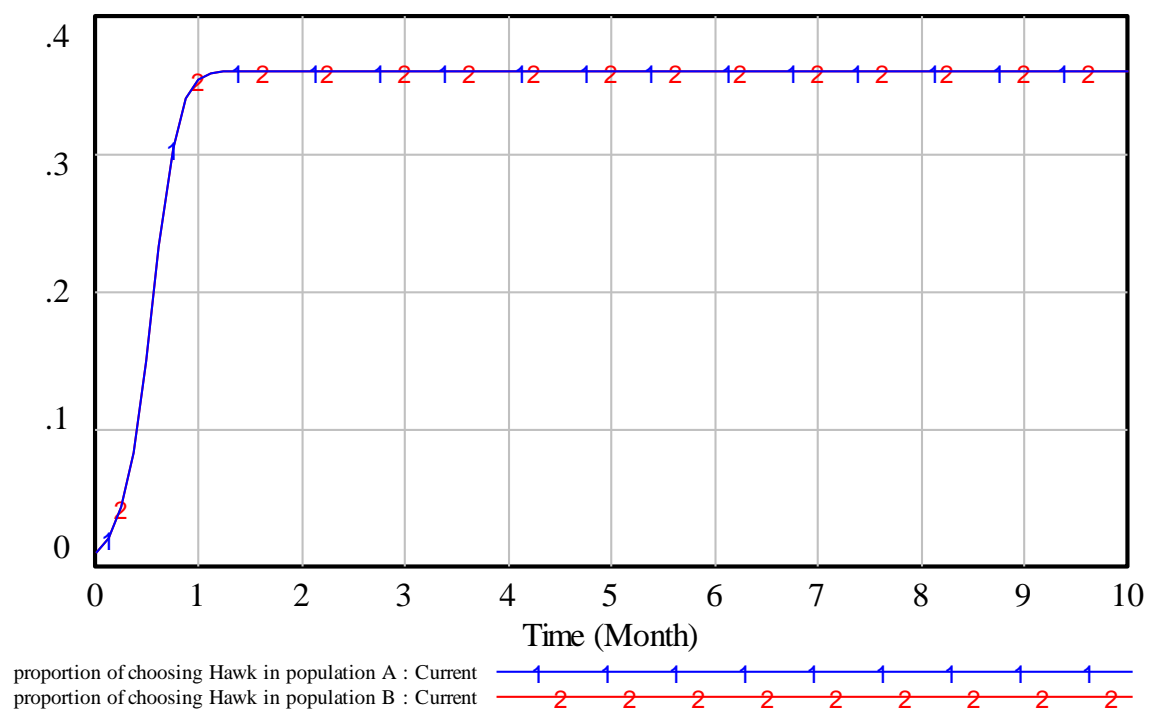

Figure 4. ET-SD model exploring game results with mutation 
The relative values of parameters were assumed instead of absolute values due to the difficulties of collecting actual costs during construction (Constantino and Pietroforte 2002; Lee et al. 2009). The initial values (payoffs) are assumed from 1 to 4 for different pricing strategies by the general contractors and original subcontractors before the simulation. Although the payoffs of change orders are influenced by factors, such as work content, profit, risk, and cooperative relationship, the trend or variant through simulations can still be applied for exploring the evolutionary dynamics between the general contractors and original subcontractors.

For the original subcontractors, the payoff of adopting SHQ must be higher than adopting SNQ. Hence, SHQ dominates SNQ. However, competition is often perceived to impact pricing levels (Laryea and Lubbock 2014). If the original subcontractor perceives that the general contractor would adopt CPB strategy, which means inquiring with another potential subcontractor, the original subcontractor might decrease the quotation strategies to be competitive. The sequence of four payoffs for the original subcontractor is HQ1 > HQ2 > NQ1 > NQ2.

However, if the quotation by another potential subcontractor is lower than SHQ, the general contractor might decide to subcontract the change orders to the potential subcontractor. As a result, the payoff (HQ2) becomes 0 . The sequence of four payoffs for the original subcontractor becomes HQ1 > NQ1 > NQ2 > HQ2.

For general contractors, the transaction cost of adopting CPB is higher than for COB because of further inquiry to another potential subcontractor. Whether the original subcontractors adopted SHQ or SNQ, the general contractors can obtain a higher payoff by adopting COB. Therefore, COB dominates CPB. Considering two different strategies of the original subcontractors, the sequence of four payoffs for the general contractors is OB2 > PB2 > OB1 > PB1.

However, if the quotation of the potential subcontractor is lower than $\mathrm{HQ} 2$ and the original subcontractor adopts SHQ, payoff (PB1) might be higher than the payoff (OB1). Here, the sequence of four payoffs for the general contractor becomes OB2 > PB2 > PB1 > OB1.

The relative values are presented as payoffs in two scenarios.

Scenario 1

The payoffs of the original subcontractors and general contractors are HQ1 > HQ2 > NQ1 > NQ2 and $\mathrm{OB} 2>\mathrm{NB} 2>\mathrm{OB} 1>\mathrm{NB} 1$, respectively, as shown in Figure 5.

\begin{tabular}{|c|c|c|c|c|}
\cline { 3 - 5 } \multicolumn{2}{c|}{} & \multicolumn{2}{c|}{ Subcontractor (S) } & \multicolumn{1}{c}{ proportion } \\
\cline { 3 - 5 } \multicolumn{2}{c|}{} & SHQ & SNQ & $x_{s}^{C}$ \\
\hline \multirow{3}{*}{ Contractor (C) } & COB & $(2,4)$ & $(4,2)$ & $1-x_{s}^{C}$ \\
\cline { 2 - 5 } & CPB & $(1,3)$ & $(3,1)$ & \\
\cline { 3 - 5 } & proportion & $x_{s}^{S}$ & $1-x_{s}^{S}$ & \\
\cline { 2 - 5 } & &
\end{tabular}

Figure 5. Payoff matrix between general contractors and original subcontractors-Scenario 1

The equilibrium solutions of the replicator dynamics in Eqs. (7) and (10) can be obtained as four pure strategies:

$$
\mathrm{s}_{1}=\left(\begin{array}{l}
0 \\
0
\end{array}\right), \mathrm{s}_{2}=\left(\begin{array}{l}
0 \\
1
\end{array}\right), \mathrm{s}_{3}=\left(\begin{array}{l}
1 \\
0
\end{array}\right), \mathrm{s}_{4}=\left(\begin{array}{l}
1 \\
1
\end{array}\right), \mathrm{s}_{\mathrm{n}} \in\left(\begin{array}{l}
\mathrm{x}_{\mathrm{n}}^{\mathrm{S}} \\
\mathrm{x}_{\mathrm{n}}^{\mathrm{C}}
\end{array}\right) .
$$

When each strategy is initially simulated in the SD model, each population presents a relatively balanced state and does not adopt the other strategy. $s_{3}$ is taken as an example and shown in Figure 6 . 
Initial balance state (s3)

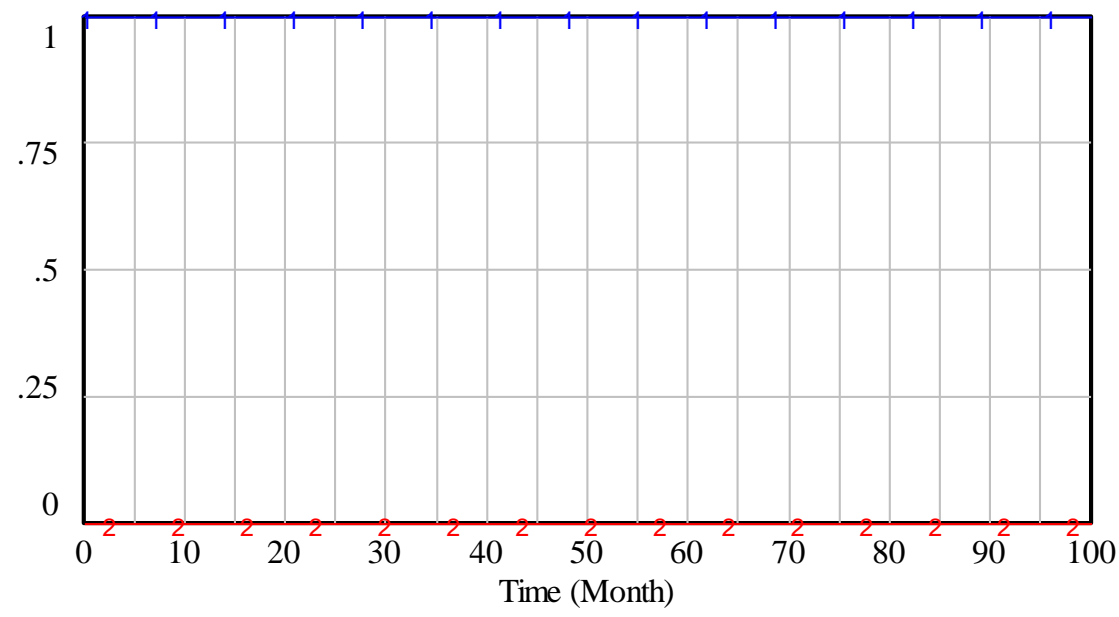

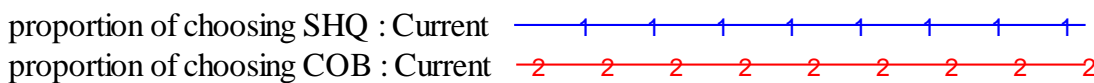

Figure 6. Initial state of pricing strategy $\left(\mathrm{s}_{3}\right)$

However, only $s_{4}$ is an ESS among the four pure strategies. As such, if $s_{4}$ mutates its initial strategy, even if the general contractors do not all adopt $\mathrm{COB}$ but some adopt $\mathrm{CPB}$, or the subcontractors do not all adopt SHQ but some adopt $\mathrm{SNQ}$, the simulation results show steadiness and the invader of CPB or SNQ eventually dies out (Figure 7).

Game results exist mutation (s4)

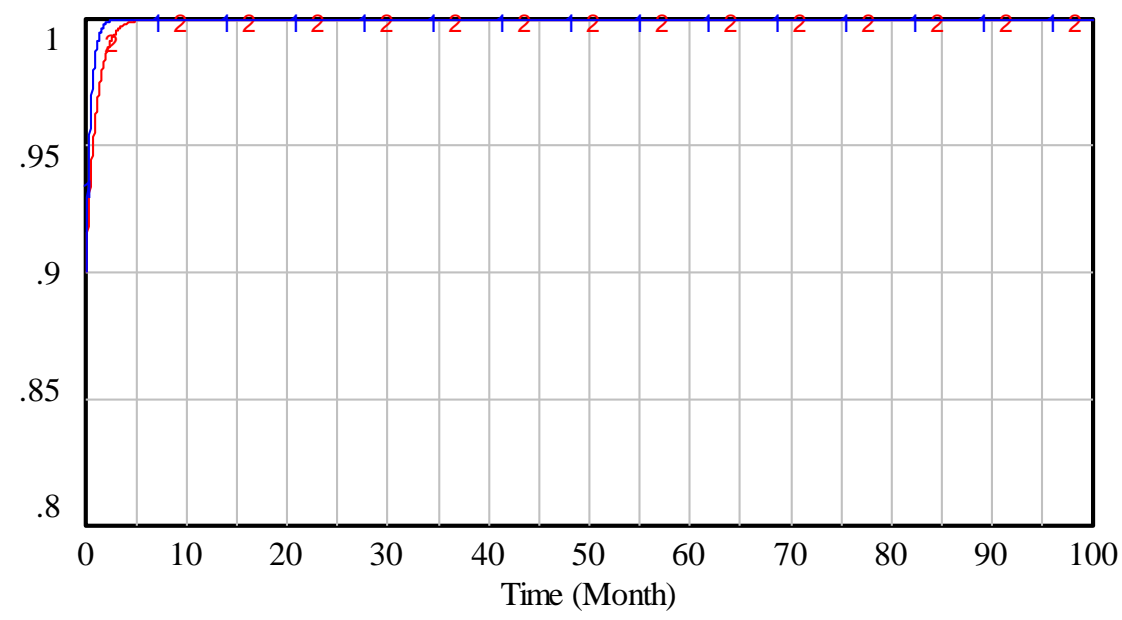

\begin{tabular}{l} 
proportion of choosing SHQ : Current \\
\cline { 2 - 4 }
\end{tabular}

Figure 7. ESS of pricing strategy $\left(s_{4}\right)$

Other strategies are not relatively steady. If some original subcontractors mutate their initial strategy in $s_{2}$, ratio $x_{2}^{S}$ changes from 0 to 0.01 and the strategy selection of original subcontractors gradually evolves toward 1 . The results after simulation are shown in Figure 8. 

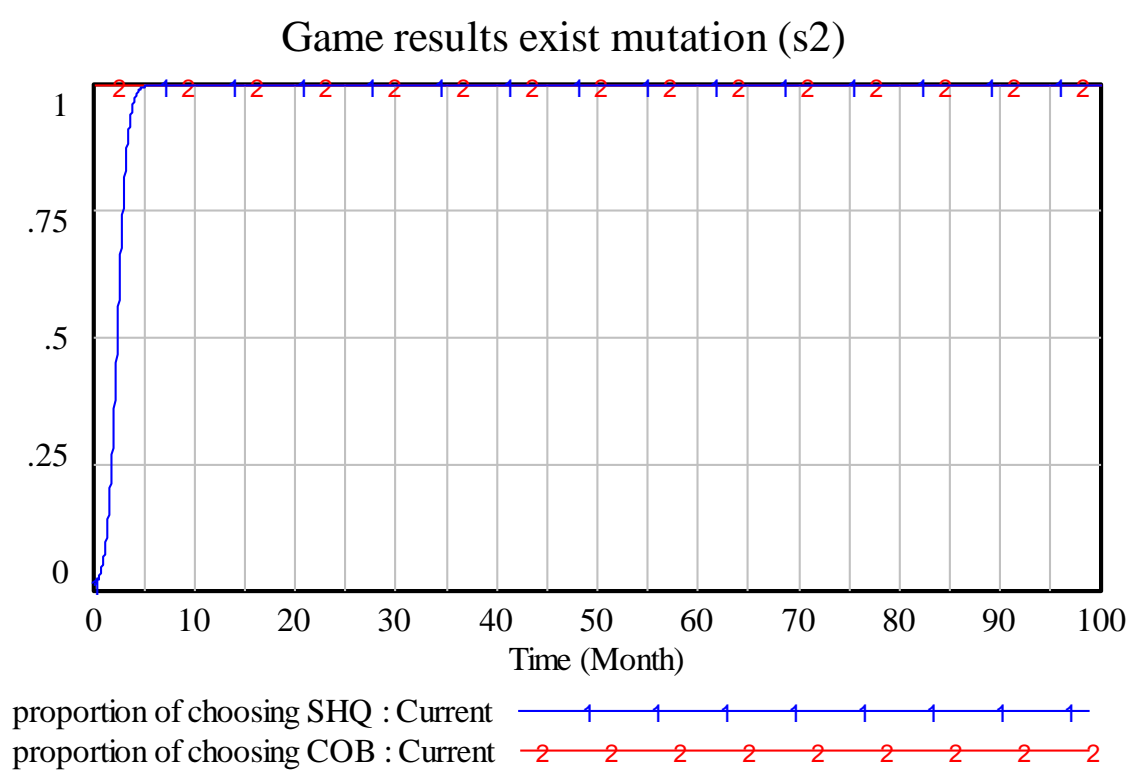

Figure 8. Evolutionary result of pricing strategy $\left(\mathrm{s}_{2}\right)$

In this scenario, the strategies SHQ and COB are both NE and ESS. Even if the general contractor realizes that the original subcontractor adopts $\mathrm{SHQ}$, the general contractor would agree to the quotation of the change order. Conversely, if the original subcontractors adopt SNQ one original subcontractor mutates the strategy and adopts $\mathrm{SHQ}$, and the whole population of original subcontractors will eventually adopt SHQ through replicator dynamics.

Scenario 2

The payoffs of the original subcontractors and general contractors are HQ1 > HQ2 > NQ2 > NQ1 and $\mathrm{OB} 2>\mathrm{NB} 2>\mathrm{NB} 1>\mathrm{OB} 1$, respectively, as shown in Figure 9.

\begin{tabular}{|c|c|c|c|c|}
\cline { 3 - 5 } \multicolumn{2}{c|}{} & \multicolumn{2}{c|}{ Subcontractor (S) } & \multicolumn{1}{c|}{ proportion } \\
\cline { 3 - 5 } \multicolumn{2}{c|}{} & SHQ & SNQ & $x_{s}^{C}$ \\
\hline \multirow{3}{*}{ Contractor (C) } & COB & $(1,4)$ & $(4,3)$ & $1-x_{s}^{C}$ \\
\cline { 2 - 5 } & CPB & $(2,1)$ & $(3,2)$ & \\
\hline & proportion & $x_{s}^{S}$ & $1-x_{s}^{S}$ & \\
\cline { 2 - 5 } & & &
\end{tabular}

Figure 9. Payoff matrix between general contractors and original subcontractors-Scenario 2

Similar with the simulation results of Scenario 1, the equilibrium solutions of the replicator dynamics in Eqs. (7) and (10) can be obtained as four pure strategies. However, none of the players have a dominating strategy. None of the four pure strategies has NE and ESS. If the general and original subcontractors mutate, few general contractors would adopt $\mathrm{COB}$ and few of the original subcontractors would adopt SHQ (e.g., $\left(\begin{array}{l}0.01 \\ 0.01\end{array}\right)$ ). The evolutionary results performed by the two populations cause continuous oscillation between strategies, as shown in Figure 10. 
Game results exist mutation (s1)

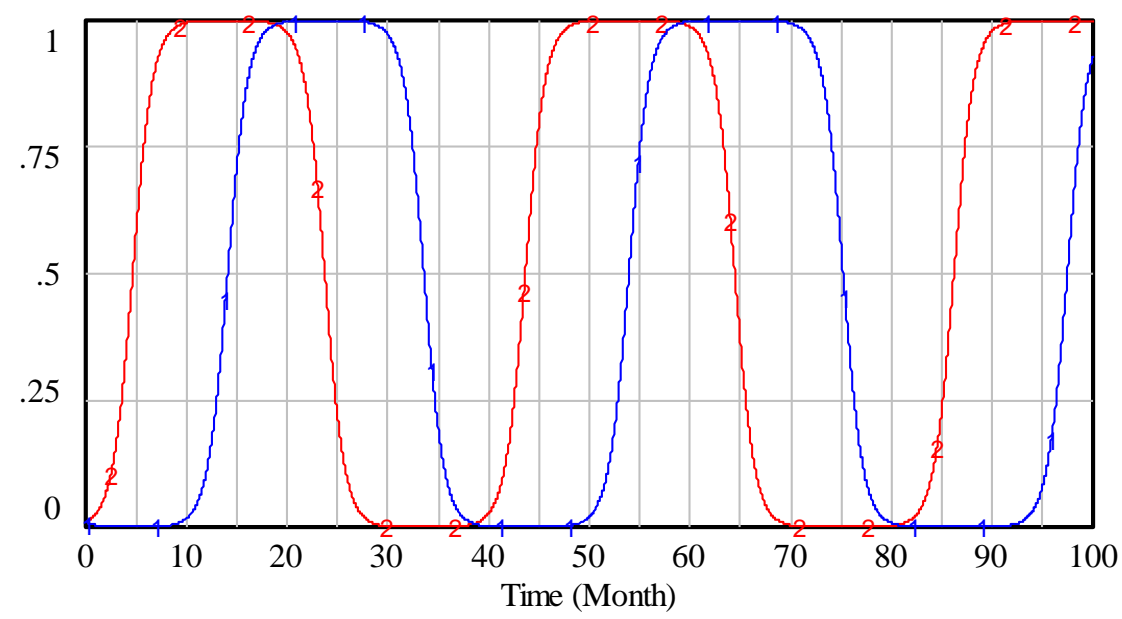

$\begin{array}{lllllllllll}\text { proportion of choosing SHQ : Current } & & 1 & 1 & 1 & 1 & 1 & 1 & 1 \\ \text { proportion of choosing COB : Current } & 2 & 2 & 2 & 2 & 2 & 2 & 2 & 2\end{array}$

Figure 10. Evolutionary result of pricing strategy $\left(\mathrm{s}_{1}\right)$ with mutation

\section{Discussion}

The results of the ET-SD model reveal that SHQ succeeds and gains a payoff with BCR if the general contractors cannot obtain more payoffs from another potential subcontractor. The strategy adopted by the general contractors depends on how much payoff can be obtained from the quotation proposed by a potential subcontractor. If change orders are complex, risky, and intricate with the existing work, the potential subcontractor might perceive difficulty to carry out the work and provide a competitive quotation. The general contractors will not obtain a higher payoff by lower cost and may eventually choose $\mathrm{COB}$ and pay a higher cost to the original subcontractors for change orders.

The selection of strategy in an evolutionary game is influenced by payoffs. To further realize the selection by general contractors and original subcontractors under different payoffs, sensitivity analysis was used to review the variant and transient time from scenario 1 to scenario 2 . When the general contractors can obtain a higher payoff from CPB instead of COB, CPB will be adopted. In such a case, the COB strategy causes the original subcontractors to receive a lower payoff from SHQ than SNQ, even getting zero payoff. Therefore, the parameters of the sensitivity analysis are to change PB1 and HQ2 in scenario 1. Simulation time is changed to 200 months for understanding the variant of evolutionary game under different parameters when the general contractors and original subcontractors mutate their strategies: $\left(\begin{array}{c}\mathrm{x}_{\mathrm{s}}^{\mathrm{S}} \\ \mathrm{x}_{\mathrm{S}}^{\mathrm{C}}\end{array}\right)=\left(\begin{array}{l}0.01 \\ 0.01\end{array}\right)$ (Table 1).

Table 1. Parameter settings of sensitivity analysis for CPB-SHQ payoffs

\begin{tabular}{lllllllllll}
\hline \multicolumn{1}{r}{ Simulation } & Current & 2 & 3 & 4 & 5 & 6 & 7 & 8 & 9 & 10 \\
Payoff & & & & & & & & & & \\
\hline PB1 (when OB1 = 2) & 1 & 1.5 & 2 & 2.1 & 2.1 & 2.1 & 2.1 & 3 & 4 & 5 \\
HQ2 (when HQ1 = 4) & 3 & 3 & 3 & 3 & 2 & 1 & 0 & 0 & 0 & 0 \\
\hline
\end{tabular}

The simulation results reveal that when PB1 increases but is still less than OB1, even if a few of the general contractors select $\mathrm{COB}$ in the beginning, the whole population eventually selects $\mathrm{COB}$ as shown by the two simulation curves "Current" and "2" in Figure 11. However, when PB1 is larger than OB1, the proportion of the population selecting COB continuously decreases (simulation curves 3 and 4) unless HQ2 decreases (simulation curves 5-7). The reduction of HQ2 increases the 
proportion of general contractors selecting $\mathrm{COB}$, but eventually they will still select $\mathrm{CPB}$ in the long-term evolution. Periodic oscillation occurs until PB1 continues to increase (simulation curves 8-10).
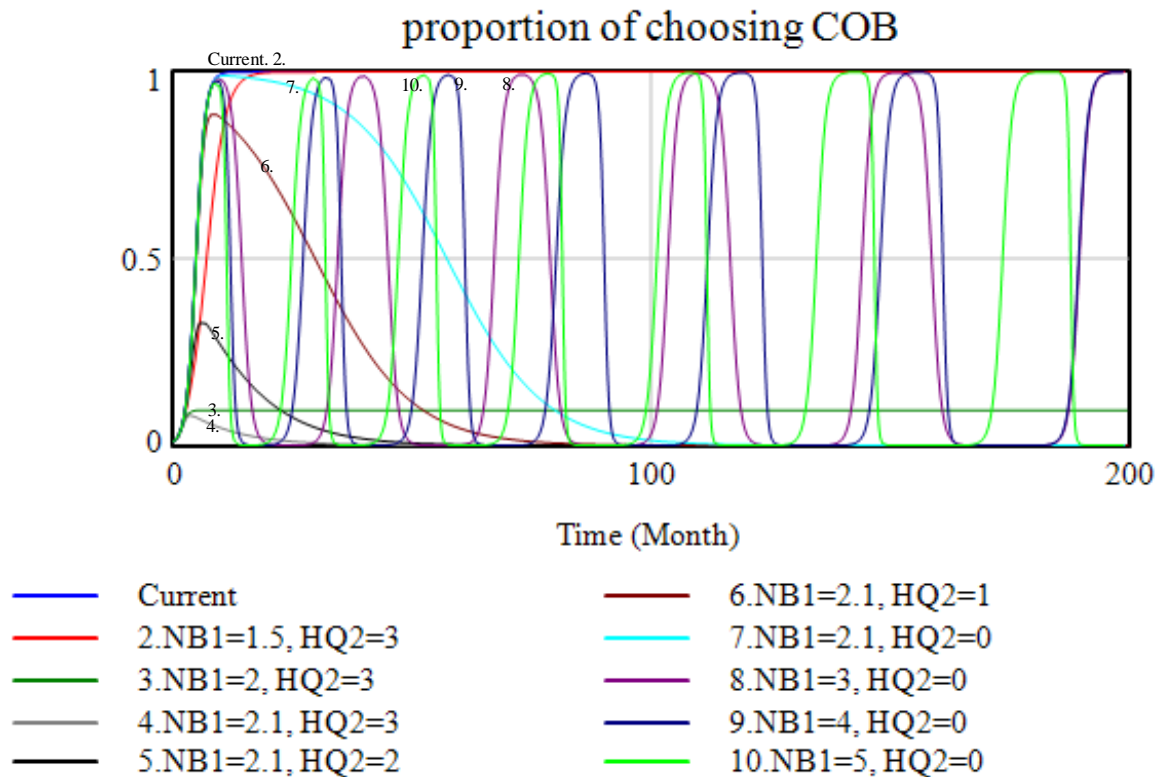

Figure 11. Results of sensitivity analysis in $\mathrm{COB}$ evolution

From the selection of the original subcontractors' strategy, although payoff PB1 obtained by the general contractors continuously increases, the evolutionary results where the original subcontractors select SHQ remain (simulation curves 1-7). The situation would not change even if the original loss of the change order and payoff $\mathrm{HQ} 2$ become 0 . The evolution results generate a periodic oscillation until the payoff PB1 is obviously larger than OB1 obtained by the general contractors, as demonstrated by simulation curves 8-10 in Figure 12.

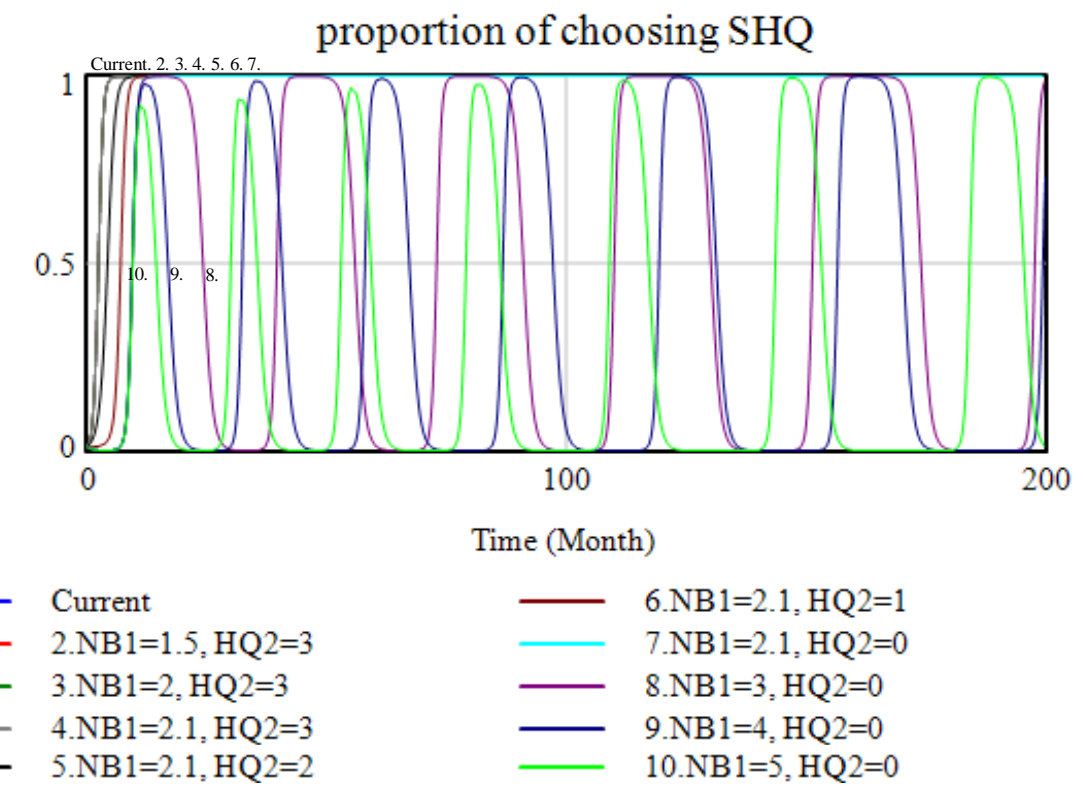

Figure 12. Results of sensitivity analysis in SHQ evolution

According to replicator dynamics, payoff with BCR cannot be eradicated by bidding management or the supervision of subcontractors. The invader will continue to increase the proportion of SHQ and obtain a higher payoff. Eventually, SHQ will become an ESS. 
When the payoff with BCR is ESS, even if the general contractor possesses better bargaining power, the state of equilibrium cannot fluctuate. Conversely, if the payoff can be restructured, the $\mathrm{BCR}$ would reduce through evolutionary dynamics.

\section{Conclusions and recommendation}

This section is not mandatory, but can be added to the manuscript if the discussion is unusually long or complex.

Change orders have been discussed previously; however, few studies have discussed pricing strategies from the unilateral perspective of the owner or contractor, and none relate to the dynamics of the pricing strategy between general contractors and subcontractors.

Although researches have revealed that the BCR can be reduced through construction management and subcontractor supervision, quotation with BCR remains popular in ecology of construction engineering.

This study investigated the pricing dynamics of change orders using the ET-SD model that, with sensitivity analysis, allowed exploring the variant trend and transient time of pricing dynamics between general contractors and original subcontractors. Results revealed that till the payoffs of pricing strategies between the general contractors and original subcontractors remain unchanged, the adopted strategy COB-SHQ reflects NE and ESS.

Although some contracts regulate a reasonable payoff and execution rule and the pricing of some change orders may be discussed after completion of work to reduce uncertainty and $\mathrm{BCR}$, the challenge remains to completely fulfill the rule considering work uncertainty, time pressure, and cooperative relationships.

This study mainly contributes in developing an ET-SD model to explore the evolutionary dynamics of pricing strategies between general contractors and original subcontractors. It also presents the key factors required to change the NE and ESS through simulation.

For general contractors, the proportion of high payoff with BCR obtained by the original subcontractors can decrease only if the cost of additional enquiry to a potential subcontractor is reduced and the payoff increased. Accordingly, the pricing of change orders can return to a reasonable quotation.

For original subcontractors, only if the change orders' work content, work environment, and interaction with general contractors can be acknowledged can they obtain a payoff with BCR from change orders.

This study also presents three important managerial insights from the proposed model.

1. From the evolutionary game perspective, the pricing strategies that general contractors tend to inquire change orders to original subcontractors, and original subcontractors tend to obtain BCR from a high quotation remain ESS. The state's proportion may not be efficiently reduced through contract management and supervision. Conversely, to decrease the proportion of high quotation by original subcontractors, general contractors should consider how to change the payoffs of pricing strategies.

2. To decrease change order payoffs with $B C R$, general contractors should optimally standardize the change orders' work content to clarify work interface and decrease the risk premium of the original and potential subcontractors.

3. Binding change orders with time pressure should be prevented. General contractors will have sufficient time to find more competitive potential subcontractors to increase its payoff. It also releases the compromise of $\mathrm{BCR}$ due to time pressure.

In construction projects, the scope or difficulty of each change order is different, and the payoff of each change order depends on the variation. The limitation of this study is that the simulation results cannot completely profile the dynamics of a specific change order. Although the payoff might be influenced by bargaining power, this study does not involve the negotiation process between 
general contractors and subcontractors; thus, the managerial value would not be discounted. Construction practitioners can apply the model to real-world cases, and payoff of each strategy can be further broken down, e.g., work content, risk, and relationships, to make the simulation results more realistic.

For some reasons, change orders may come from owners. As this model has only considered general contractors and original subcontractors, future research can consider the interaction among the three populations or combine methods such as regression analysis or artificial neural network to forecast the change orders' pricing and contribute to the extant research on construction change orders.

Author Contributions: The following statements specify individual contributions of authors. “Conceptualization, Yu Che Lai; methodology, Yu Che Lai; software, Chien-Liang Lin and Yu Che Lai; formal analysis, Yu Che Lai; writing - original draft preparation, Yu Che Lai; writing-review and editing, Yu Che Lai and Chien-Liang Lin; visualization, Yu Che Lai; supervision, Chien-Liang Lin; project administration, Chien-Liang Lin; All authors have read and agreed to the published version of the manuscript."

Funding: "This research received no external funding"

Conflicts of Interest: “The authors declare no conflict of interest."

\section{References}

1. Shen, W., Tang, W., Wang, S., Duffield, C., Hui, F. and You, R. "Enhancing trust-based interface management in international engineering-procurement-construction projects." J. Constr. Eng. Manage., 2017, 143(9), 04017061-1-12.

2. Gould, N. et al., "Dispute resolution in the construction industry", Thomas Telford Publishing, 1999.

3. Hanna, A.S. and Gunduz, M. "Impact of Change Orders on Small Labor-Intensive Projects." J. Constr. Eng. Manage. 2004, 130(5), 726-733.

4. Hanna, A.S., Richard, C., Peterson, P.A., and Nordheim, E.V. "Quantitative definition of projects impacted by change orders." J. Constr. Eng. Manage., 2002, 128(1), 57-64.

5. Hinze, J. and Tracey, A. "The contractor-subcontractor relationship: The subcontractor's view." J. Constr. Eng. Manage., 1994, 120(2), 274-287.

6. Thomas, H. and Napolitan, C. "Quantitative Effects of Construction Changes on Labor Productivity." J. Constr. Eng. Manage., 10.1061/(ASCE)0733-9364, 1995, 121:3(290), 290-296.

7. Ibbs, C. “Quantitative Impacts of Project Change- Size Issues." J. Constr. Eng. Manage., 1997, 123(3), 308-311.

8. Hanna, A., Russell, J., Gotzion, T., and Nordheim, E. "Impact of change orders on labor efficiency for mechanical construction." J. Constr. Eng. Manage., 10.1061/(ASCE)0733-9364, 1999, 125(3), 176-184.

9. Hsieh, T., Lu, S. and Wu, C. "Statistical analysis of causes for change orders in metropolitan public works." International Journal of Project Management, 2004, 22(2004), 679-686.

10. Ibbs, W. "Impact of change's timing on labor productivity." J. Constr. Eng. Manage., 2005, 131(11), 1219-1223.

11. Ibbs, C., Wong, C and Kwak, Y. "Project change management system." Journal of Management in Engineering, 2001, 17(3), pp. 159-165.

12. Wu, C.H. "A dynamic evaluation model for design change on public construction." Ph.D. thesis, Dept. of Civil Engineering, National Central University. Taoyuan, Taiwan, 2004.

13. Du, J., El-Gafy, M. and Zhao, D. “Optimization of change order management process with object-oriented discrete event simulation-case study." J. Constr. Eng. Manage., 2015, 142(4), 05015018-1-15.

14. Lee, H., Seo, M., Park, M., Ryu, H. and Kwon, S. "Transaction-cost-based selection of appropriate general contractor: Subcontractor relationship type." J. Constr. Eng. Manage., 2009, 135(11), 1232-1240.

15. Ho, S.P. and Liu, L.Y., "Analytical model for analyzing construction claims and opportunistic bidding." $J$. Constr. Eng. Manage., 2004, 130(1), 94-104.

16. Crowley, L. G., and Hancher, D. E. "Risk assessment of competitive procurement." J. Constr. Eng. Manage., 1995, 121(2), 230-237.

17. Lo, W., Lin, C. and Yan, M. "Contractor's opportunistic bidding behavior and equilibrium price level in the construction market." J. Constr. Eng. Manage., 2007, 133(6), 409-416. 
18. Lo, W, and Yan, M.R. "Evaluating qualification-based selection system-A simulation approach" J. Constr. Eng. Manage., 2009, 135(6), 458-465.

19. Kale, S. and Arditi, D. "General contractors' relationships with subcontractors: A strategic asset." Constr. Manage. Econ., 2001, 19(5), 541 - 549.

20. Ling, F. Y., Ning, Y., Ke, Y. and Kumaraswamy, M. M. “Modeling relational transaction and relationship quality among team members in public projects in Hong Kong." Autom. Constr., 2013, 36, 16 - 24.

21. Ren, $Z$ and Anumba, C. "Learning in multi-agent systems a case study of construction claims negotiation." Advanced Engineering Informatics, 2002, 16(2002), 265-275.

22. Paul, L. Construction contract claims changes \& dispute resolution. 2nd Edition, ASCE Press, 1998.

23. Duah, D. and Syal, M. "Direct and Indirect Costs of Change Orders." Journal of Professional Issues in Engineering Education and Practice, 2017, 22(4), 67-73.

24. Rasmusen, E. Games and information: an introduction to game theory, ISBN 957-11-3290-X, 2003.

25. Guo, S., Zhang, P. and Yang, J. "System dynamics model based on evolutionary game theory for quality supervision among construction stakeholders." Journal of Civil Engineering and Management, 2018, 24(4), 318-330.

26. Friedman, D. “Evolutionary games in economics.” Econometrica, 1991, 59(3), 637-666.

27. Maynard Smith, J., \& Price G. The logic of animal conflict. Nature, 1973, 146, 15-18.

28. Stephenson, D. "Coordination and evolutionary dynamics: When are evolutionary models reliable." Games and Economic Behavior, 2018, 113(2019), 381-395.

29. Roger A. McCain. Game theory: a non-technical introduction to the analysis of strategy, ISBN 957-729-568-1. South Western, 2006.

30. Lazar, F. "Project partnering: Improving the likelihood of win-win outcomes." Journal of Management in Engineering, 2000, 16(2), 71-83.

31. Kim, D. and Kim, D. "A system dynamics model for a mixed-strategy game between police and driver." System Dynamics Review, 1997, 13(1), 33-52.

32. Tian, Y., Govindan, K. and Zhu, Q. "A system dynamics model based on evolutionary game theory for green supply chain management diffusion among Chinese manufacturers." Journal of Cleaner Production, 2014, 80(2014), 96-105.

33. Liu, Q., Li, X. and Hassal, M. "Evolutionary game analysis and stability control scenarios of coal mine safety inspection system in China based on system dynamics." Safety Science, 2015, 80(2015), 13-22.

34. Mohammadi, A., Shirazi, A., Talebnezhad, A., Javaheri, A. and Javanmardi, E. "The combination of system dynamics and game theory in analyzing oligopoly markets." Management Science Letters, 2016, 6(2016), 265-274. 